\title{
Fracture Characteristics and Anisotropy in Notched Glass Fiber Reinforced Plastics
}

\author{
Sérgio Renan Lopes Tinô ${ }^{a, b *}$, Eve Maria Freire de Aquino ${ }^{a}$ \\ aPrograma de Pós-graduação em Engenharia Mecânica, Universidade Federal do Rio Grande do Norte - UFRN, \\ Campus Universitário-Centro de Tecnologia, Lagoa Nova, Natal, RN, Brazil \\ ${ }^{b}$ Instituto Federal de Goiás - IFG, Luziânia, GO, Brazil
}

Received: June 12, 2014 - Revised: November 30, 2014

\begin{abstract}
The damage mechanism of reinforced plastics may be present in many different ways, since it depends on many factors. Highlights may be given to the effect of stress concentration in of geometric discontinuity in the sections of these structural elements, which in general always leads to certain characteristics of the fracture. In the case of glass fiber reinforced plastics (GFRP) it is expected the same tendency, beyond the influence of reinforcement and its internal orientation in the layers (anisotropy). The aims of this work are detailed study of the influence of the holes (longituninal section) in the characteristic fracture in GFRP submitted to tensile loading. Three different configurations of composite laminates were studied: two reinforced with Eglassfiber bidirectional textil fabric and the other only with short mats, also Eglassfiber. The results showed the influence of all parameters listed above in the final fracture characteristics and residual properties.
\end{abstract}

Keywords: Anisotropy, Glass Fiber Reinforced Plastics, Fracture, Hole, Residual Strength

\section{Introduction}

The continuous search for new materials that combine high performance and easy conformation (manufacture) has been the focus of a large number of studies in recent decades. Composite materials and reinforced plastics have been important in these investigations, given that they meet these requirements as well as their added advantage of being low weight, an indispensable parameter in numerous structural applications.

Glass fiber reinforced plastics (GFRP) are among the most widely used because of their varied properties and low fiber cost when compared with other synthetic fibers such as carbon and aramid.

Fracture characteristics of composite materials are strongly influenced by the properties of their components, such as type of reinforcement and matrix, proportion of these components and most importantly fiber distribution and orientation (anisotropy) ${ }^{1}$. Anisotropy becomes a limiting factor when applying composite materials as laminar structure.

In addition to this complexity, the application of these elements may also exhibit sharp differences in the crosssectional area, such as holes and notches. These types of geometric discontinuities are often necessary to establish links between structural project mechanisms and may generate serious problems in the distribution of internal stresses to the structural element, originating "stress concentration areas" ${ }^{2-6}$. This phenomenon has a direct influence on final fracture, since it concentrates the fracture region in the geometric discontinuity section, primarily in polymer composites composed of a material considered "brittle"

*e-mail: sergiorlt@yahoo.com.br
The effect of stress concentration becomes much more complex in composite materials, since it does not depend only on geometry and type of loading, as in conventional materials ${ }^{8,9}$. For this reason, some theoretical and experimental models have been seeking to quantify it based on the damage zone, that is, the final fracture region ${ }^{10}$.

Based on this, many works have been developed involving experimental and numerical analysis in order to quantify the phenomenon of stress concentration in composites through mainly theories of failure like point stress criterion (PSC) and average stress criterion (ASC) ${ }^{10-12}$. Highlight can be made that these analyzes are mostly made of composite materials reinforced only with synthetic fibers like carbon; hence, the importance of models also applied to GFRP used in composite structures.

This study investigates the influence of central holes in the longitudinal area (with a reduced cross-sectional area) on fracture characteristics of two composite laminates, under uniaxial tensile loading. The configurations of these laminates are defined as a composite laminate based only on E-glass (ML) fiber mats (short) with seven layers, whereas the other laminate is composed of bidirectional fabric of the same type of fiber (FL) and 4 layers. The influence of anisotropy is studied for the case of the FL composite, where different fiber orientations are observed in its layers in relation to the direction of the applied load. Fiber orientations in composites are defined as $\mathbf{F L} \pm \mathbf{4 5}^{\circ}$ composite and $\mathbf{F L ~} \mathbf{0 / 9 0 ^ { \circ }}$ composite.

Fiber orientation in their layers (configuration) with respect to applied load direction may simultaneously influence the previously mentioned properties ${ }^{13}$.

To make it easier to understand the properties under study, composites were defined as ML and FL for the case 
of composites without a central hole, while HML and HFL refer to composites with central hole.

Finally, microscopic analyses of final fracture characteristics were conducted to understand the effect of hole in the composite section on final fracture. Analyses were carried out using optical microscopy.

In this work, the phenomenon of stress concentration was studied, considering that the alterations suffered in relation to the laminates strength have as basis the Residual Strength- $R S$ calculation, experimentally, using the concepts determined by ${ }^{14}$.

\section{Material and Methods}

The hand layup process was used to manufacture the composite laminates, which were fabricated by Tecniplas Nordeste Indústria e Comércio Ltda in the form of two $1.0 \mathrm{~m}^{2}$ plates. The raw materials used were orthophthalic polyester resin (Novapol L120) as matrix and E-glass fibers as reinforcement. One plate was defined as a composite laminate of short E-glass fiber mats $\left(450 \mathrm{~g} / \mathrm{m}^{2}\right)$ denominated ML. The other plate was an E-glass fiber reinforced composite laminate with bidirectional fabric $\left(600 \mathrm{~g} / \mathrm{m}^{2}\right)$ designated FL. The ML plate was manufactured with seven layers and mean thickness of $5.0 \mathrm{~mm}$, while the FL plate was built with only four layers and mean thickness of $3.7 \mathrm{~mm}$.

The reason for choosing a smaller number of layers for the FL composite is due to an ASTM D5766-0 $7^{14}$ standard testing method requirement, stating that it is advisable to use a hole diameter $(6.0 \mathrm{~mm}) /$ laminate thickness ratio between 1.5 and 3.0. For the ML composite, the choice was based on the fact that this number of layers is traditionally used in industry, primarily in the manufacture of medium-sized reservoirs.

In the case of the FL composite, two configurations with different fiber layer orientations with respect to applied load direction were created: $\mathbf{F L ~} \mathbf{0} / \mathbf{9 0}^{\circ}$ and $\mathbf{F L} \pm \mathbf{4 5}^{\circ}$. It is important to underscore that for both $\mathbf{F L}$ composites the same plate was used to obtain test specimens and that the orientation of the $\pm 45^{\circ}$ and $0 / 90^{\circ}$ fiber occurred as a function of cut direction, resulting in the anisotropy effect.
Test specimens destined for hole geometries were $\mathbf{H M L}$, HFL $0 / \mathbf{9 0}^{\circ}$ and $\mathbf{H F L} \pm \mathbf{4 5}^{\circ}$. Holes were made by enlarging an initial $2.0 \mathrm{~mm}$ pre-hole to the standard diameter ${ }^{14}$ of 6.0 $m m$. Diamond thread drills were used to avoid possible irregularities on the hole surface. Delaminations and microcracks after drilling were not observed through macroscopic and microscopic analyzes. After appropriate test specimen dimensions were obtained, the regions where the cut was applied were smoothed and polished.

Figure 1 shows the test specimen cutting scheme for the FL and ML configurations.

The uniaxial tensile test was performed to find the tensile strength and Young's modulus (in the direction of load application) of the laminate under several conditions of study. Therefore, eight specimens for each condition were confectioned, obtaining five tests considered as valid according to the technical standard. Displacement velocity in uniaxial tensile testing was $1.0 \mathrm{~mm} / \mathrm{min}$ (standard) for all test specimens. All tests were carried out at ambient temperature using a mechanical universal testing machine (Shimadzu AGI-250 KN) with maximum capacity of $25 \mathrm{~T}$.

Dimensions of test specimens without a hole were defined by ASTM D 3039-08 ${ }^{15}$, while for those with a hole ASTM D 5766- $07^{14}$ was used. All specimens had a useful length (gage) of $127 \mathrm{~mm}$ and widths of $36 \mathrm{~mm}$ (HML, HFL 0/90 ${ }^{\circ}$, HFL $\left.\pm 4^{\circ}\right)$ and $25 \mathrm{~mm}\left(\mathrm{ML}, \mathrm{FL} \mathrm{0/90}{ }^{\circ}\right.$, FL $\left.\pm 4^{\circ}\right)$. All test specimen dimensions were within the standard tolerance of $\pm 1 \%$.

The experimental Residual Strength $(R S)$, according to $^{14,16}$, for all configurations studied was calculated from the Equation 1:

$$
R S=\frac{\sigma_{N}}{\sigma_{U N}}
$$

Considering that $\sigma_{N}$ is the tensile strength found in the tests with the hole (notched strength) and $\sigma_{U N}$ is the tensile strength found in the tests without the hole (unnotched strength). It is highlighted that all parameters mentioned were calculated in the largest cross-sectional area of the specimens, according to the standard.

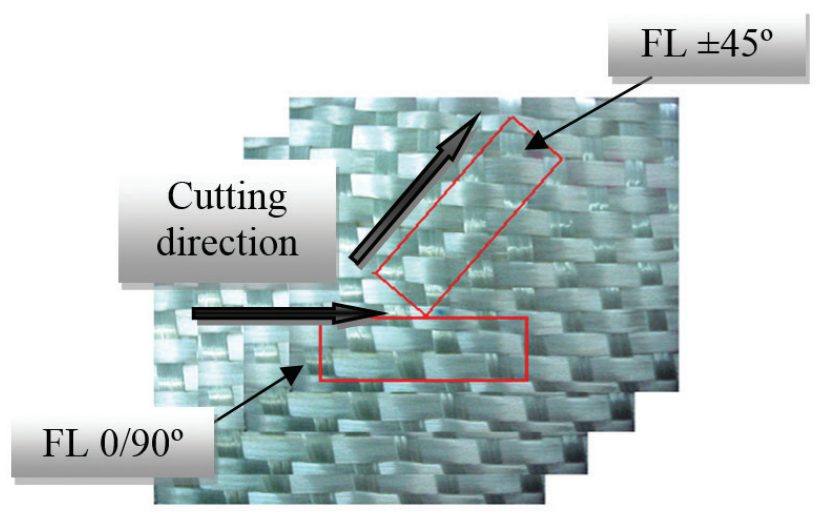

(a)

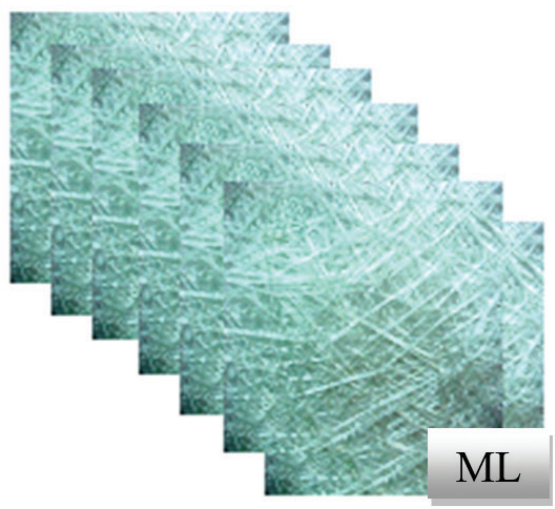

(b)

Figure 1. (a) Configurations and cut direction for $\mathbf{F L ~} \mathbf{0} / \mathbf{9 0}^{\mathbf{}}$ and $\mathbf{F L} \pm \mathbf{4 5 ^ { \circ }}$, (b) $\mathbf{M L}$ configuration. 
Microscopic and macroscopic analyses in the fracture region of the test specimens were conducted to study final fracture characteristics (pre-fractured specimens). An Olympus MG optical microscope was used for microscopic analysis.

\section{Results and Discussion}

\subsection{Uniaxial Tensile Tests - notched and unnotched specimens}

With regard to the uniaxial tensile test for especimens without hole $\left(\mathbf{M L}, \mathbf{F L ~} \mathbf{0 / 9 0}{ }^{\circ}, \mathbf{F L} \pm \mathbf{4 5}^{\circ}\right)$ and with hole (HML, HFL 0/90 ${ }^{\circ}, \mathbf{H F L} \pm \mathbf{4 5}^{\circ}$ ) the mean values obtained for ultimate tensile strength are shown in Table 1, as well as their respective dispersions.

It is noteworthy that the dispersions refer to the absolute difference between the maximum and minimum values obtained in the test for each parameter analyzed. It is also worth pointing out that for all the configurations. Dispersion percentages, in general, are within levels specific to polymer composites only based on glass fibers ${ }^{16}$.

To determine ultimate tensile strength in each specimen with hole was determined by the maximum tension developed in the laminate is determined in the largest area of the cross section and not in the section where the stress concentration phenomenon occurs. This is because a study based on this phenomenon requires calculation of the stress concentration factor $(K)$ to determine maximum stress, which requires methodology and technical tests or specific experiments.

The results obtained for $R S$ were: 0.7 for $\mathbf{M L}, 0.82$ for FL $\mathbf{0} / \mathbf{9 0}^{\circ}$, and 0.89 for $\mathbf{F L} \pm \mathbf{4 5}^{\circ}$, respectively. The Figure 2 shows better the values.

Overall, the loss of strength for $\mathbf{F L} \pm 45^{\circ}$ was much less than for the others (only $11.43 \%$ ), but even so, it should be a value to consider with respect to structural projects, since the hole had a negative influence on final mechanical response. Another factor that can influence behavior is the strong presence of shear overlapping that of traction due to the orientation of the fibers against the loading direction. It is worth noting that this behavior is typical of a composite considered orthotropic with reinforcement at $45^{\circ}$ in relation to the load application ${ }^{17}$.

Regardless of configuration, in all cases, the hole had a negative influence with respect to ultimate strength. Note that for $\mathbf{M L}$, this influence was more pronounced than for FL configuration, demonstrating that this is more relevant in isotropic materials.

The FL 0/90 ${ }^{\circ}$ configuration displayed superior mechanical behavior in relation to the others, which was expected considering the reinforcement type (bidirectional fabric) and the fiber direction with respect to load application. However, the smallest percentage difference between ultimate tensile strengths $(11 \%)$, only considering the hole, was found for the laminate at $\pm 45^{\circ}$.

\subsection{Fracture analysis of configurations without hole}

Figure 3 shows some of the post-test specimens of the ML. Damage was concentrated in the final fracture region, with no significant variations observed in other areas.

According to ASTM D 3039-08 ${ }^{15}$, LGM (Lateral Gage Middle) was the type of fracture observed, which is perfectly valid for the test.

The fragile fracture in the ML exhibited maximum deformation of $4 \%$ of final fracture. Figure 4 a depicts an optical micrograph of a region near the final fracture, showing cracks spreading through the fiberglass layers.

Figure $4 \mathrm{~b}$ shows that cracks initially spread perpendicularly to load direction, then become intralaminar split spreading in the direction of the applied load (longitudinally). It was also observed that when cracks spread longitudinally they caused a "rupture or nonadhesion" on the fiber/matrix interface, characterizing adhesive fracture.

Cracks that spread only in the matrix are called cohesive matrix fractures and those that cross fibers longitudinally are known as cohesive fiber fractures (Figure 4b).

The ML configuration showed no interlayer delamination, which was expected since it is composed only of fiberglass mats, causing little discrepancy between interlaminar stresses.

Fractures in the $\mathbf{F L ~} \mathbf{0} / \mathbf{9 0}^{\circ}$ configuration initiated with progressive cracking perpendicular to load application,

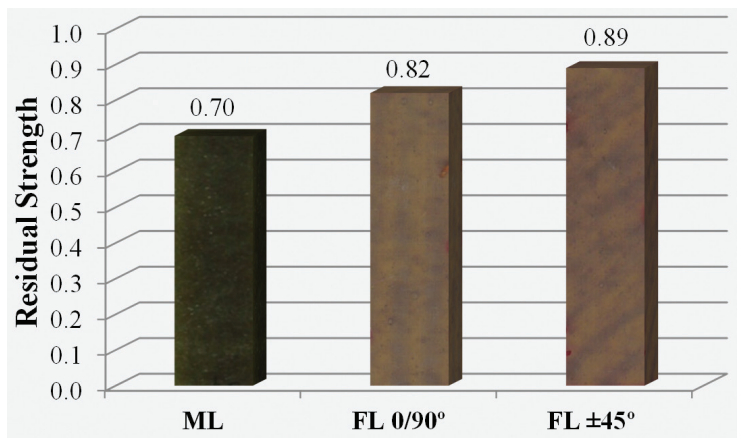

Figure 2. Residual Strength- $R S$ diagram to all configurations.

Table 1. Tensile strength (mean values) and respective dispersions.

\begin{tabular}{cccc}
\hline Specimen & Tensile Strength $(\boldsymbol{M P a})$ & Specimen & Tensile Strength $(\boldsymbol{M P a})$ \\
\hline ML & 90.13 & HML & 62.74 \\
Dispersion (\%) & 7.47 & Dispersion (\%) & 11.71 \\
FL $0 / 90^{\circ}$ & 186.59 & HFL 0/90 & 152.99 \\
Dispersion (\%) & 15.13 & Dispersion (\%) & 20.77 \\
FL $\pm 45^{\circ}$ & 76.14 & HFL $\pm 45^{\circ}$ & 67.44 \\
Dispersion (\%) & 8.89 & Dispersion (\%) & 13.68 \\
\hline
\end{tabular}




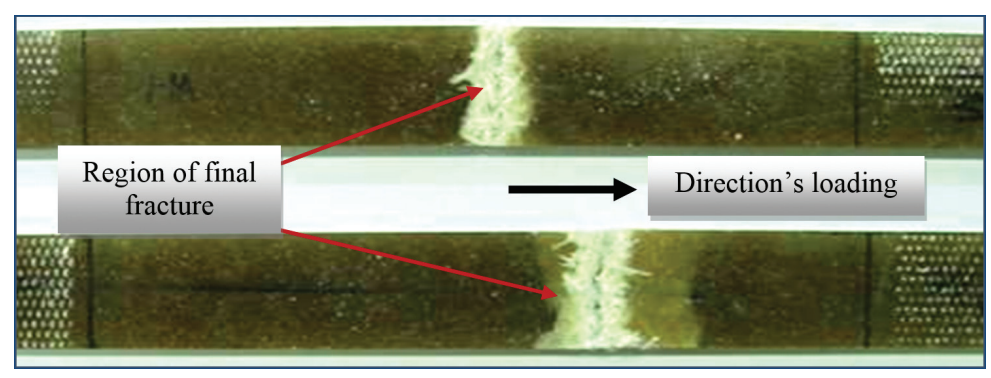

Figure 3. Post-test specimens of the ML configuration.

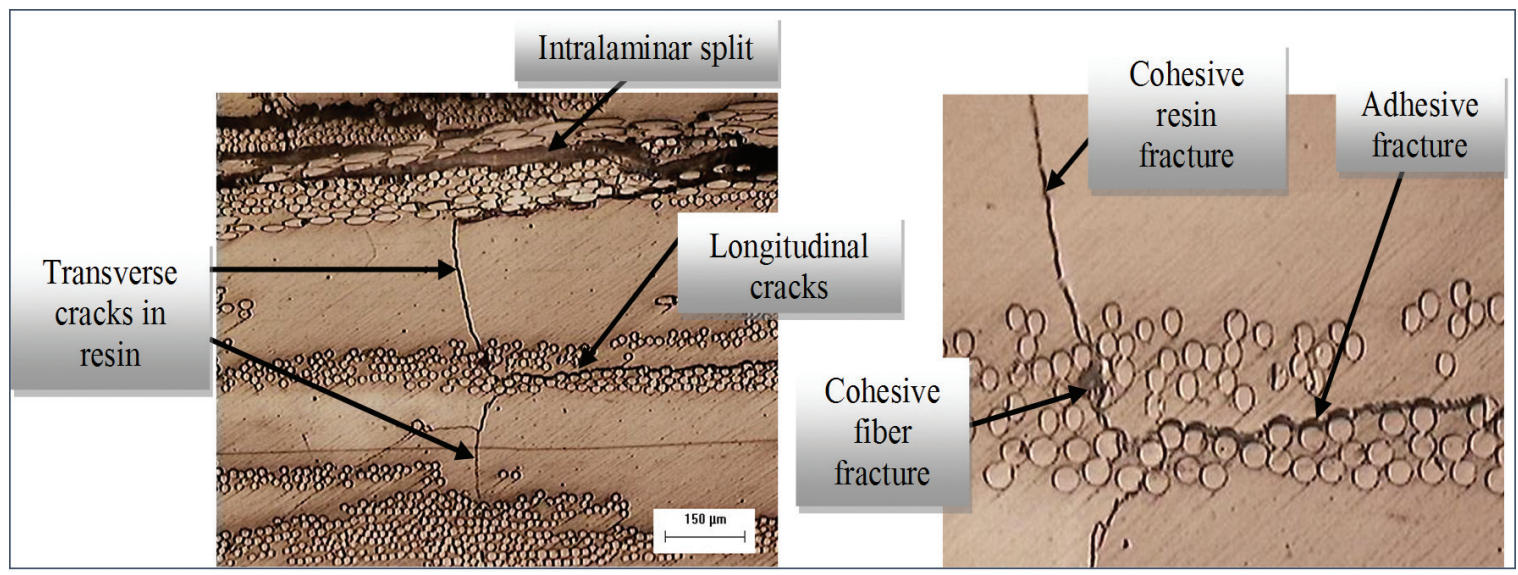

(a)

(b)

Figure 4. (a) Region near final fracture, (b) cohesive and adhesive fracture near final fracture region - Uniaxial tensile of ML configuration.

spreading along the entire length of the test specimen (Figure 5), exhibiting a state of saturation before the final fracture. They also displayed fiber pull-out phenomenon in the final fracture region, characteristic damage in fabricbased polymer composites. This fiber pull-out becomes noticeable after test specimens are removed from the machine clamps.

Figure 6 shows the final fracture region of the $\mathbf{F L ~} \mathbf{0} / \mathbf{9 0}^{\circ}$, which according to ASTM D $3039-08^{15}$, is the LGM mode and therefore valid for this type of test.

In addition to matrix cracking, microscopic fracture analysis revealed adhesive fractures, delamination and fiber pull-out.

Optical microscopy showed that delaminations occur when transverse cracks in the matrix spread to the interface between composite laminate layers (Figure 7a). The adhesive fracture (non-adhesion to the fiber/matrix interface) is shown in Figure 7b.

Despite the existence of manufacturing defects in the composite, Figure $7 \mathrm{~b}$, they caused no damage during loading, even though an adhesive fracture was observed very close to them, but in a region without any apparent damage.

Fracture characteristics of the $\mathbf{F L} \pm \mathbf{4 5 ^ { \circ }}$ were similar to those of the $\mathbf{F L ~} \mathbf{0} / \mathbf{9 0}^{\circ}$ configuration, that is, cracking in the entire matrix occurs progressively, exhibiting a saturation state before final fracture (Figure 8). Being a fabric-

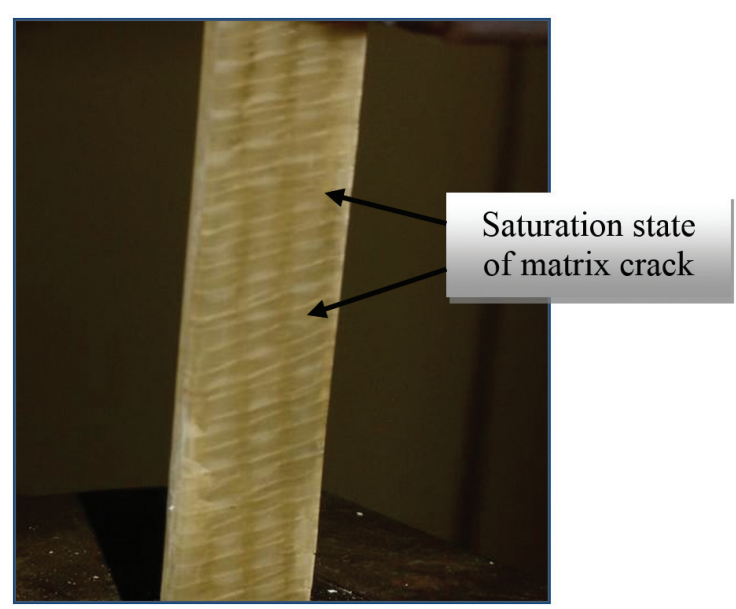

Figure 5. Saturation state of transverse matrix cracking in the FL $\mathbf{0} / 90^{\circ}$ configuration.

reinforced composite, it also displayed the fiber pull-out phenomenon, Figure 8, although less intense than the FL $\mathbf{0} / \mathbf{9 0}^{\mathbf{}}$. According to ASTM D 3039-08 ${ }^{15}$ an LGM fracture was also observed in the configuration.

Microscopic fracture analysis of this configuration showed no interlayer delaminations. All cracks occurred at $45^{\circ}$ (Figure 9), in the direction of shear and fiber orientation. 


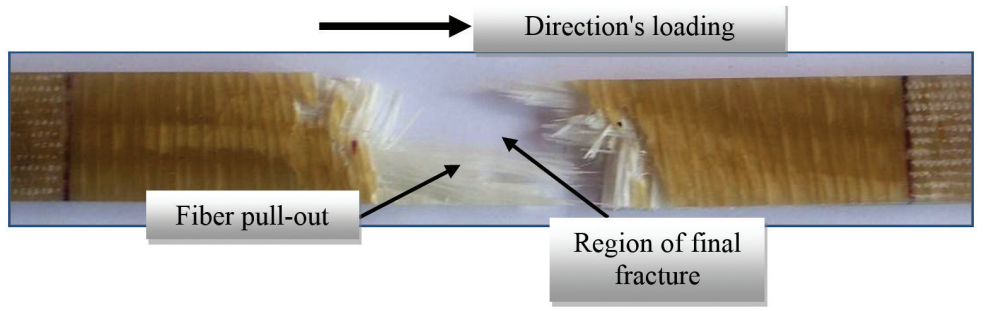

Figure 6. Final fracture characteristics of the FL $\mathbf{0 / 9 0 ^ { \circ }}$ configuration.

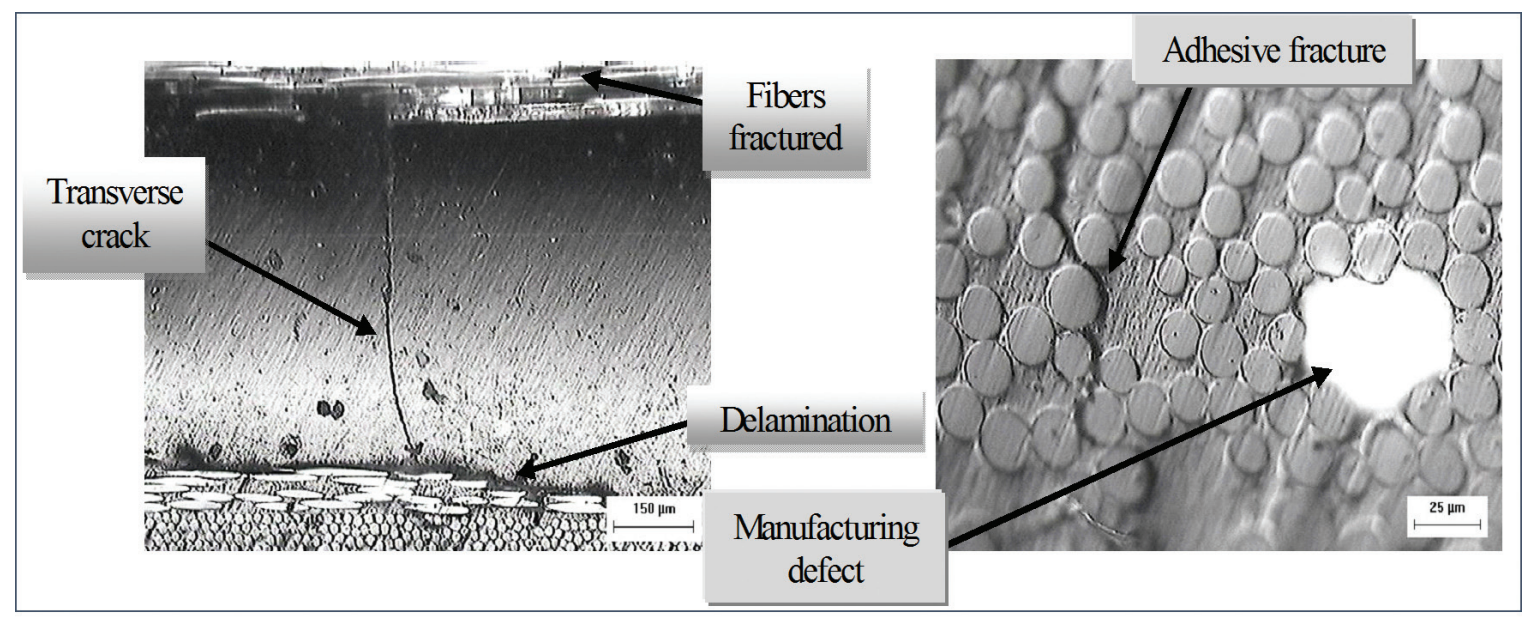

(a)

(b)

Figure 7. (a) Fracture characteristics, (b) adhesive fiber fracture and manufacturing defect. FL $\mathbf{0} / \mathbf{9 0}^{\mathbf{0}}$ configuration.

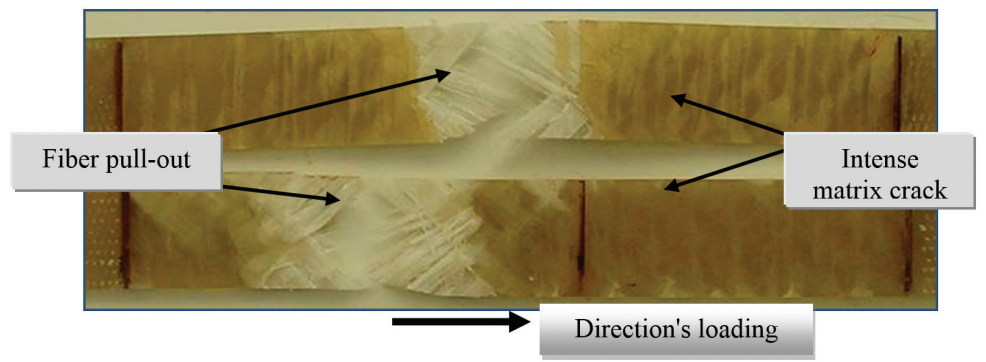

Figure 8. Macroscopic fracture analysis the $\mathbf{F L} \pm \mathbf{4 5}^{\circ}$ configuration.

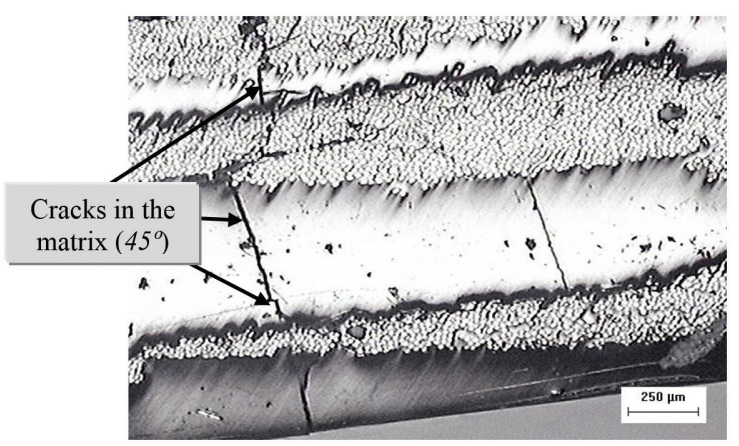

Figure 9. Microcracks at $45^{\circ}$ in the $\mathbf{F L} \pm \mathbf{4 5}^{\circ}$ configuration.
As cracks spread they gave rise to adhesive and cohesive fractures (matrix and fibers), as well as splits between strand intersections.

An important characteristic of this configuration was the presence along the entire length of the test specimens of split in the strand intersections region due to strong shearing that occurs in the reinforcement direction at $45^{\circ}$. Figure 10 demonstrates the effect of this strand intersections fragility owing to longitudinal and interlaminar splits. It was also observed that adhesive fractures in the fiber/matrix interface and cohesive fractures in the fiber and matrix originate in these splits. 


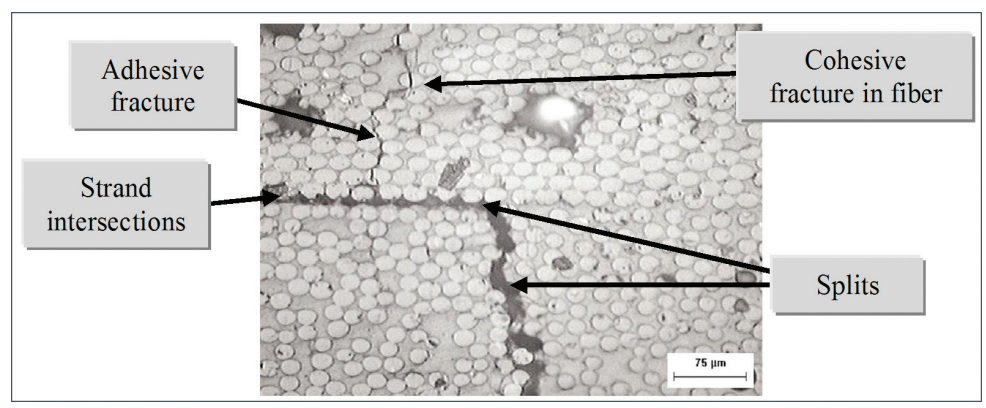

Figure 10. Splits, adhesive and cohesive fractures in the $\mathbf{F L} \pm \mathbf{4 5 ^ { \circ }}$ configuration.

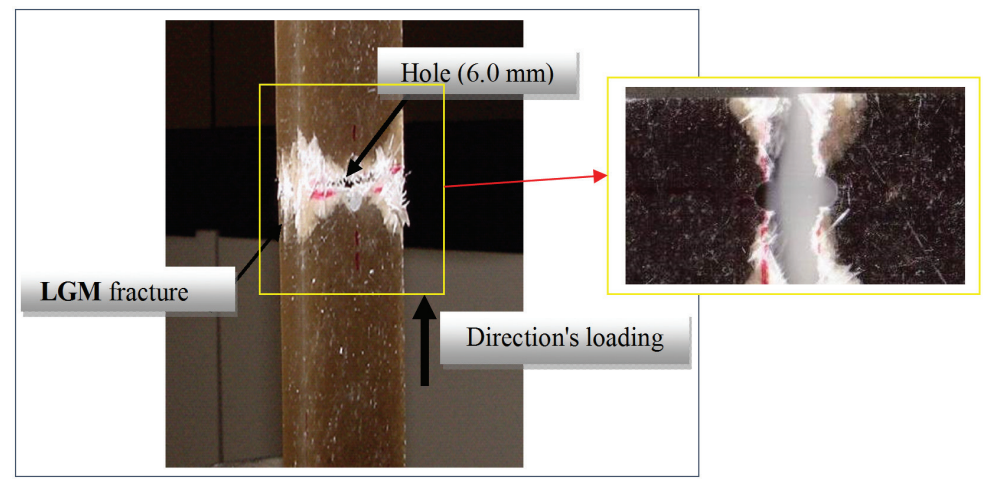

Figure 11. Post-test final fracture characteristics - HML configuration.

\subsection{Fracture analysis for configurations with hole}

Macroscopic analysis of final fracture characteristics for the HML configuration showed localized damage, which was expected due to the type of reinforcement used (randomly distributed short fiber mats).

This fracture is classified as LGM and is valid only if it is located in the hole section, owing to the stress concentration effect that occurs there. Figure 11 shows final fracture characteristics of the HML configuration after the uniaxial tensile test.

This type of configuration can be considered to have macroscopically isotropic behavior in relation to elastic properties (characteristic of deformation). Damage that occurred in the HML was concentrated in the cross-section where the hole is located, according to ASTM D 5766- $07^{14}$ standard testing. Figure 12 shows a micrograph of the final fracture region of the HML, where a very high concentration of cracks can be observed in the matrix along with the presence of splits.

The macroscopic study of final fracture characteristics for the HFL $0 / \mathbf{9 0}^{\circ}$ shows damage that initiates with matrix cracks, transverse to the applied load, which spread progressively along the entire length of the test specimen, exhibiting saturation state before final fracture.

Thus, as with the HML configuration, the final fracture (LGM mode) in the HFL $\mathbf{0 / 9 0 ^ { \circ }}$ configuration occurs in the hole section, as foreseen in the standard.

Figure 13 depicts the test specimen after uniaxial tensile testing of the HFL $\mathbf{0 / 9 0}{ }^{\circ}$. Macroscopic analysis of fracture

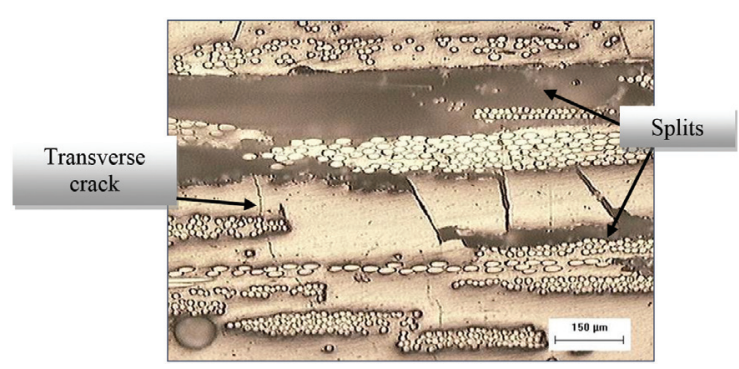

Figure 12. Splits and transverse cracks in the HML configuration.

characteristics shows the fiber pull-out phenomenon, typical of fabric-reinforced composites ${ }^{7}$.

It is also important to note that the presence of a hole in the configuration did not significantly alter final fracture behavior when compared to the FL 0/90 ${ }^{\circ}$. However, as shown in Figure 14, the final fracture region is saturated in the matrix, underscoring that these transverse cracks are more intense in the hole region, characterizing the stress concentration phenomenon. Microscopic analysis of the HFL $0 / \mathbf{9 0}^{\circ}$ configuration shows high concentration of splits in the final fracture region of the matrix (Figure 15).

Figure 16 shows a test specimen during uniaxial tensile testing of the $\mathbf{H F L} \pm \mathbf{4 5}^{\circ}$ configuration, in which cracks initially form in the hole section, where stresses are concentrated.

Macroscopic analysis of final fracture characteristics for the $\mathbf{H F L} \pm \mathbf{4 5}^{\circ}$ also shows damage initiating with matrix 


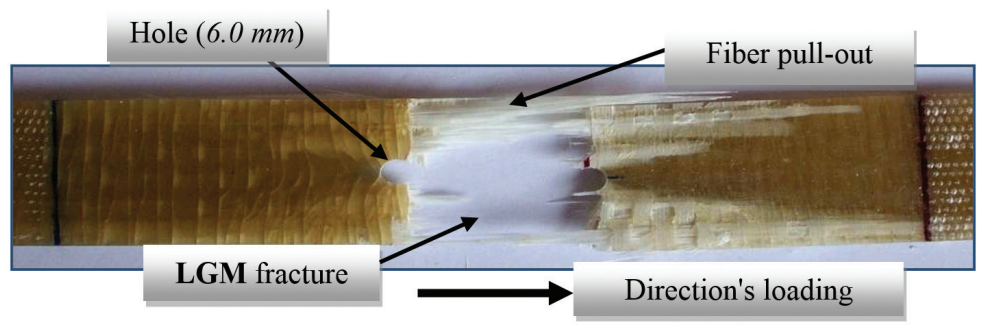

Figure 13. Final fracture region - HFL $0 / 90^{\circ}$ configuration.

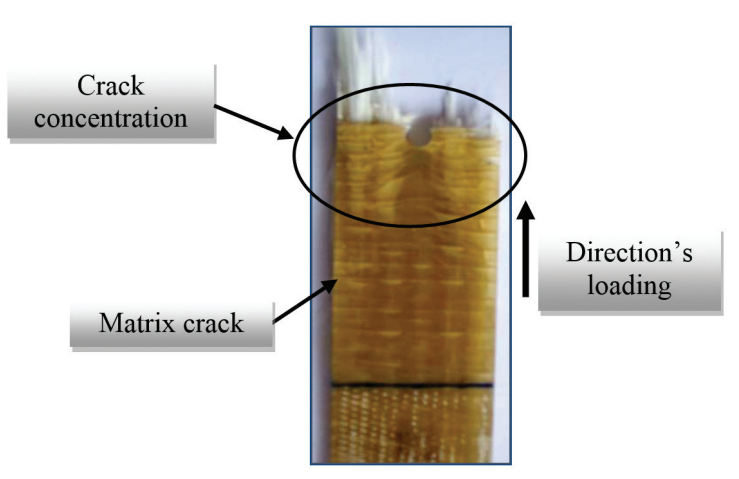

Figure 14. Matrix cracks in the HFL $0 / 90^{\circ}$ configuration.

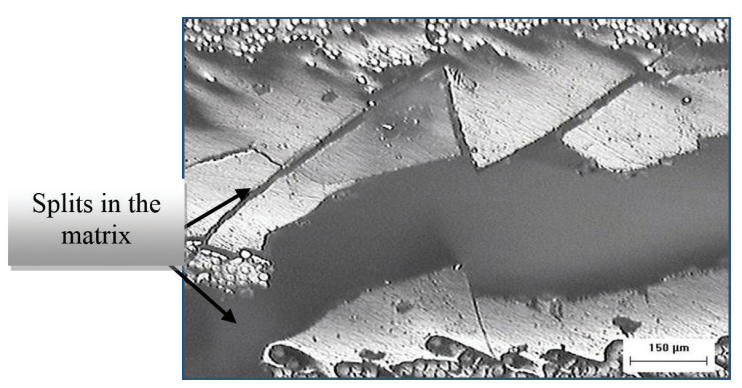

Figure 15. Splits in the matrix. HFL 0/90 ${ }^{\circ}$ configuration.

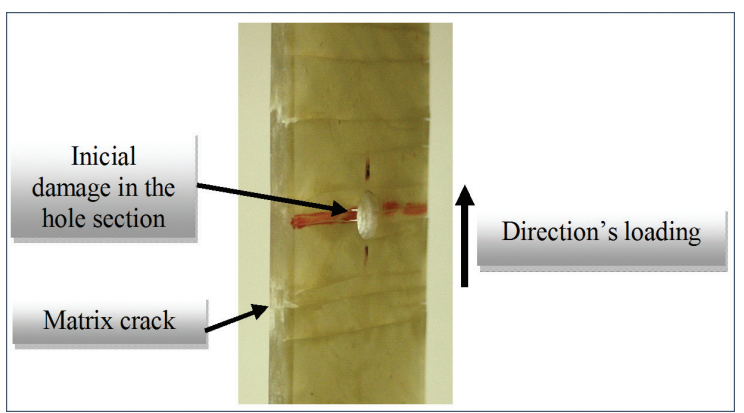

Figure 16. Initial damage in the hole section - HFL $\pm \mathbf{4 5}^{\circ}$ configuration.

cracks (Figure 17). These progressively spread along the entire test specimen, behavior that repeated itself for all bidirectional fabric-reinforced composites, with or without a hole. This configuration also exhibited matrix crack saturation before final fracture.
Final fracture of the $\mathbf{H F L} \pm \mathbf{4 5}^{\circ}$ configuration (LGM mode) was concentrated in the hole section, in accordance with the standard, that is, lateral in the middle of the gage, which is perfectly valid for this test (Figure 17).

Figure 17 shows final fracture characteristics in the hole section for the $\mathbf{H F L} \pm \mathbf{4 5}^{\circ}$. Fiber pull-out was also observed in all bidirectional fabric reinforced composites studied here.

With respect to microscopic analysis, Figure 18 shows that, in addition to reaching the reinforcement layer (intralaminar crack), initial cracking provoked matrix cracks that spread at approximately $45^{\circ}$, following fiber orientation.

Another aspect to consider is the fact that $\mathbf{F L} \pm \mathbf{4 5}{ }^{\circ}$ displays less intense damage, principally in matrix cracking, when compared to $\mathbf{F L ~} \mathbf{0} / \mathbf{9 0}^{\circ}$. This fracture characteristic prevailed in the two cases, i.e., with and without hole. The shear stresses for the $\mathbf{F L} \pm \mathbf{4 5}^{\circ}$ have direct influence on the final damage and residual strength.

\subsection{Comparison of fracture characteristics for the configurations analyzed}

Figure 19 shows fracture characteristics observed in the configurations under study, with the aim of determining the influence of the hole and/or anisotropy existing in the composites.

The presence of a center hole in the configurations analyzed did not significantly change final fracture characteristics, but rather how it spread along the entire length of the test specimens. In the case of test specimens with geometric discontinuity, fractures were concentrated in the region near the hole, where matrix cracks were spaced closer together due to the effect of stress concentration.

With respect to the configurations used, there were significant differences when all the composites were compared, given that fiber pull-out was only observed in composites with anisotropy. Delamination, another fracture characteristic, was observed only in the $\mathbf{F L ~} \mathbf{0} / 90^{\circ}$ configuration.

The presence of elements that can concentrate stress in composite materials must be considered in any configuration and independently of its degree of anisotropy, although ${ }^{18}$ considers that for discontinuous pre-impregnated carbon/epoxy, stress concentration occurs due to heterogeneity of the material (in relation to reinforcement distribution) and not because of the existence of a circular hole and that, therefore, considers the material insensitive to the notch. 


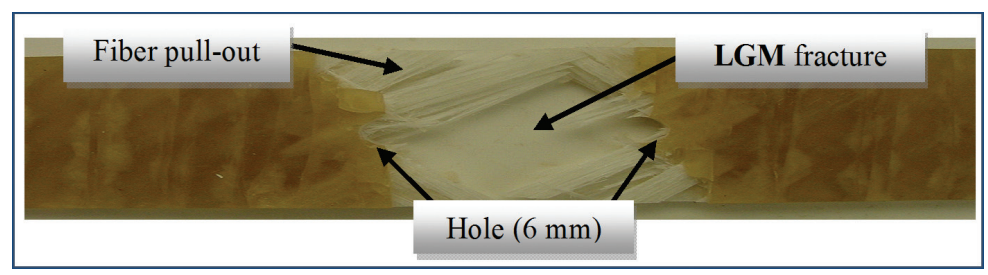

Figure 17. Fiber pull-out phenomenon in the $\mathbf{H F L} \pm \mathbf{4 5}^{\circ}$ configuration.

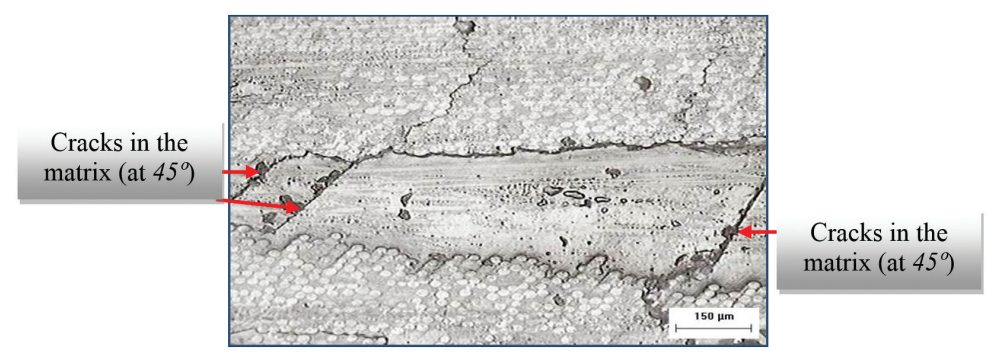

Figure 18. Matrix cracks in the reinforcement direction - $\mathbf{H F L} \pm \mathbf{4 5 ^ { \circ }}$ configuration.

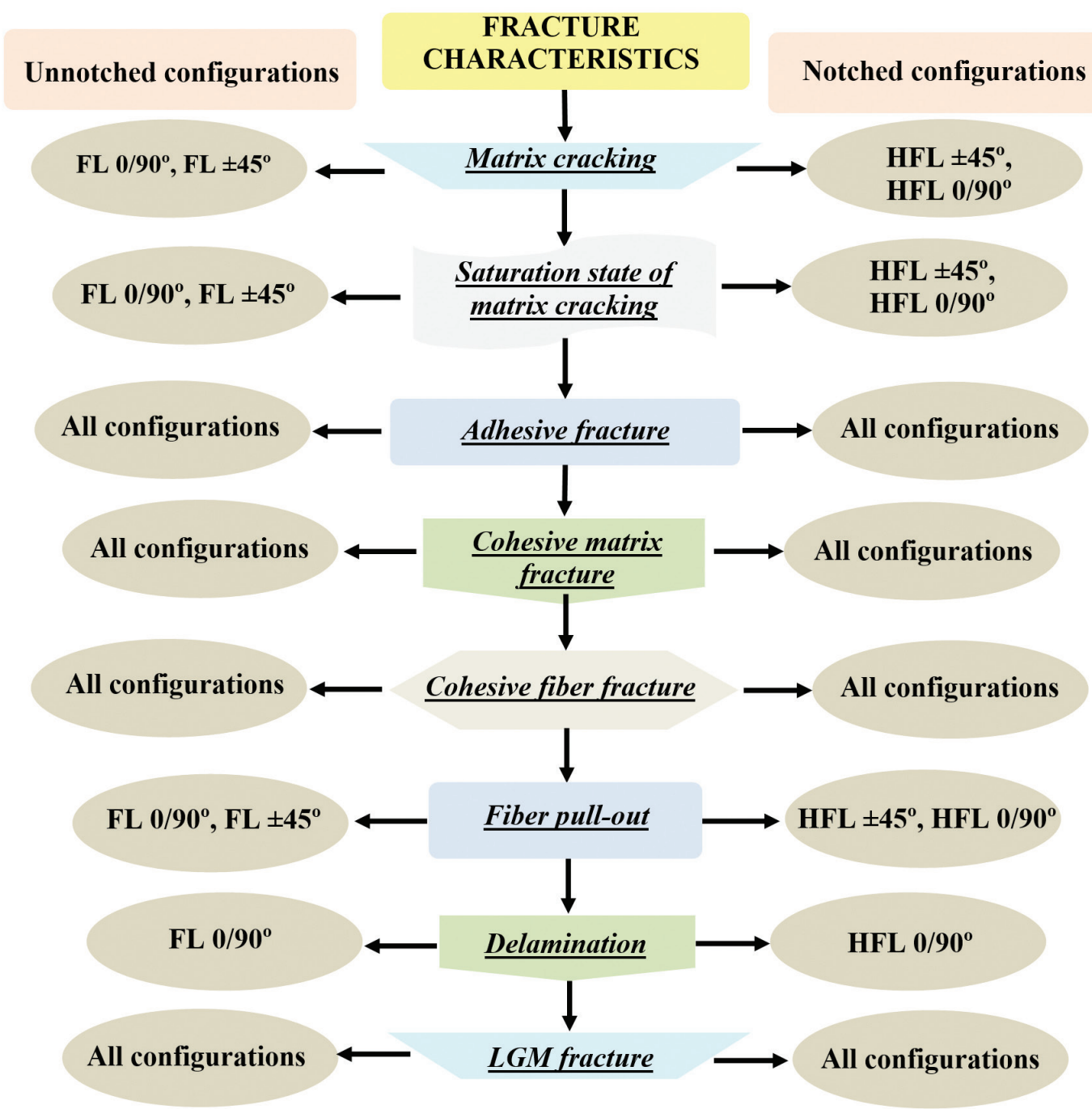

Figure 19. Comparison of damage mechanisms in the composites under study. 


\section{Conclusions}

The following conclusions can be drawn from the study results:

- Experimental Residual Strength showed the influence of the material configuration, the largest being observed for $\mathbf{F L} \pm \mathbf{4 5}^{\circ}$.

- For the uniaxial tensile test, the hole had a negative influence on the mechanical properties of strength, i.e., load support of the material. This behavior is based on tensile strength losses of $30 \%, 18 \%$, and $11 \%$ for the $\mathbf{M L}, \mathbf{F L} \mathbf{0} / \mathbf{9 0}{ }^{\circ}$, and $\mathbf{F L} \pm \mathbf{4 5 ^ { \circ }}$ configurations, respectively.

- For the configurations studied the presence of anisotropy and existence of continuous fibers in the loading direction alleviate the loss of tensile strength with hole in its longitudinal section (with reduction of the cross section), since the greatest loss was recorded for ML.

- ML, HML, FL 0/90 ${ }^{\circ}$, HFL 0/90 ${ }^{\circ}$, FL $\pm 45^{\circ}$ and HFL $\pm \mathbf{4 5}^{\circ}$ configurations fractures generally exhibited LGM mode final fracture;

- Micrographic fracture analysis showed the presence of cohesive matrix and fiber fractures and adhesive (fiber/matrix interface) fractures in the other composites studied, since delaminations (non-

\section{References}

1. Herakovich CT. Mechanics of fibrous composites. New York: Ed. Wiley; 1997. 460 p.

2. Zhao JH, Wang XF, Dharani LR and Wei J. Notch stress concentrations and failure characteristics in laminates with triple parallel notches. Composites Science and Technology. 2000; 60(15):2865-2872. http://dx.doi.org/10.1016/S02663538(00)00161-5.

3. Yan F and Pitchumani R. Effects of interphase formation on the modulus and stress concentration factor of fiber-reinforced thermosetting-matrix composites. Composites Science and Technology. 2004; 64(10-11):1437-1452. http://dx.doi. org/10.1016/j.compscitech.2003.09.027.

4. Toubal L, Karama M and Lorrain B. Stress concentration in a circular hole in composite plate. Composite Structures. 2005; 68(1):31-36. http://dx.doi.org/10.1016/j. compstruct.2004.02.016.

5. Pihtili H. Calculation and Comparison of Stress Concentration Factors in Composite Inverted-tooth Chain Link Plates with Various Dimensions. Journal of Reinforced Plastics and Composites. 2008; 27(18):1953-1962. http://dx.doi. org/10.1177/0731684407087584.

6. Hufner DR and Accorsi ML. A progressive failure theory for woven polymer-based composites subjected to dynamic loading. Composite Structures. 2009; 89(2):177-185. http:// dx.doi.org/10.1016/j.compstruct.2008.07.023.

7. Aquino EMF and Tinô SRL. Descontinuidade Geométrica nos Compósitos Poliméricos: Resposta Mecânica e Característica da Fratura. In: Proceedings of the IX Congreso Iberoamericano de Ingeniería Mecánica - CIBIM; 2009. Las Palmas de Gran Canaria Anais; 2009. v. 1. p. 12/2-12/9.

8. Awerbuch J and Madhukar MS. Notched strength of composite laminates: Predictions and experiments - A review. Journal of adhesion between laminate layers) occurred only in FL 0/90 and HFL 0/90

- With regard to fracture behavior of the laminates under study, intense cracking was observed in the matrix along the entire length of the test specimen only in bidirectional fabric-reinforced composites, with characteristics peculiar to the composite at $\pm 45^{\circ}$, where cracking occurred in the reinforcement direction due to shear forces in the direction of the reinforcement used;

- Matrix saturation occurs only in fiberglass fabricbased composites, irrespective of a hole, but is more concentrated in the hole section, owing to the effect of stress concentration;

- The pull-out phenomenon was recorded only in the fiberglass fabric-based composite (anisotropic);

- In general form, the comparative study of fracture characteristics shows that the presence of a hole was more significant for anisotropic composites (FL 0/90 ${ }^{\circ}$ and $\mathbf{F L ~} \pm \mathbf{4 5}^{\circ}$ configurations), giving rise to a more intense fracture process.

\section{Acknowledgements}

The authors acknowledge the financial support provided by $\mathrm{CNPq}$.

Reinforced Plastics and Composites. 1985; 4(1):3-159. http:// dx.doi.org/10.1177/073168448500400102.

9. Nuismer RJ and Whitney JM. Uniaxial Failure of Composite Laminates Containing Stress Concentration, in Fracture Mechanics of Composites, ASTM STP 593. Philadelphia: ASTM; 1975. p. 117-142.

10. Shin CS and Wang CM. An Improved Cohesive Zone Model for Residual Notched Strength Prediction of Composite Laminates with Different Orthotropic Lay-ups. Journal of Composite Materials. 2004; 38(9):713-736. http://dx.doi. org/10.1177/0021998304031635.

11. Hallett SR, Green BG, Jiang WG and Wisnom MR. An experimental and numerical investigation into the damage mechanisms in notched composites. Composites. Part A, Applied Science and Manufacturing. 2009; 40(5):613-624. http://dx.doi.org/10.1016/j.compositesa.2009.02.021.

12. Mollenhauer D, Iarve EV, Kim R and Langley B. Examination of ply cracking in composite laminates with open holes: a Moire' interferometric and numerical study. Composites. Part A, Applied Science and Manufacturing. 2006; 37(2):282-294. http://dx.doi.org/10.1016/j.compositesa.2005.06.004.

13. Yeh HY and Rashid HN. Effect of t-stress on damage zone size predictions of notched laminated composites. Journal of Reinforced Plastics and Composites. 2006; 25(1):89-98. http:// dx.doi.org/10.1177/0731684406055458.

14. American Society for Testing and Materials -ASTM. D 576607: Standard Test Method for Open Hole Tensile Strength of Polymer Matrix Composite Laminates. West Conshohocken; 2007.

15. American Society for Testing and Materials - ASTM. D 303908. Standard Test Method for Tensile Properties of Polymer Matrix Composite Materials. West Conshohocken; 2008. 
16. Tinô SRL, Fontes RS and Aquino EMF. Theories of failure average stress criterion and point stress criterion in notched fiber-reinforced plastic. Journal of Composites Materials. 2013. http://dx.doi.org/10.1177/0021998313501920.

17. Hufner DR and Accorsi ML. A progressive failure theory for woven polymer-based composites subjected to dynamic loading. Composite Structures. 2009; 89(2):177-185. http:// dx.doi.org/10.1016/j.compstruct.2008.07.023.

18. Feraboli P, Peitso E, Cleveland T, Stickler PB and Halpin JC. Notched behavior of prepreg-based discontinuous carbon fiber/epoxy systems. Composites. Part A, Applied Science and Manufacturing. 2009; 40(3):289-299. http://dx.doi. org/10.1016/j.compositesa.2008.12.012. 